\title{
Ah, Internet !
}

Comment interpréter cette expression, avec défiance ou avec soulagement?

Bien sûr, c'est le "ah » de désespoir qui s'échappe quand on pense aux bonimenteurs de toutes espèces qui s'y trouvent et aux propositions qui nous sont faites. Il n'y a pas que l'Orient qui nous livre des médicaments qui n'en sont pas. La question se pose souvent sur la véracité des informations.

En tant que prescripteur professionnel, je vais systématique-
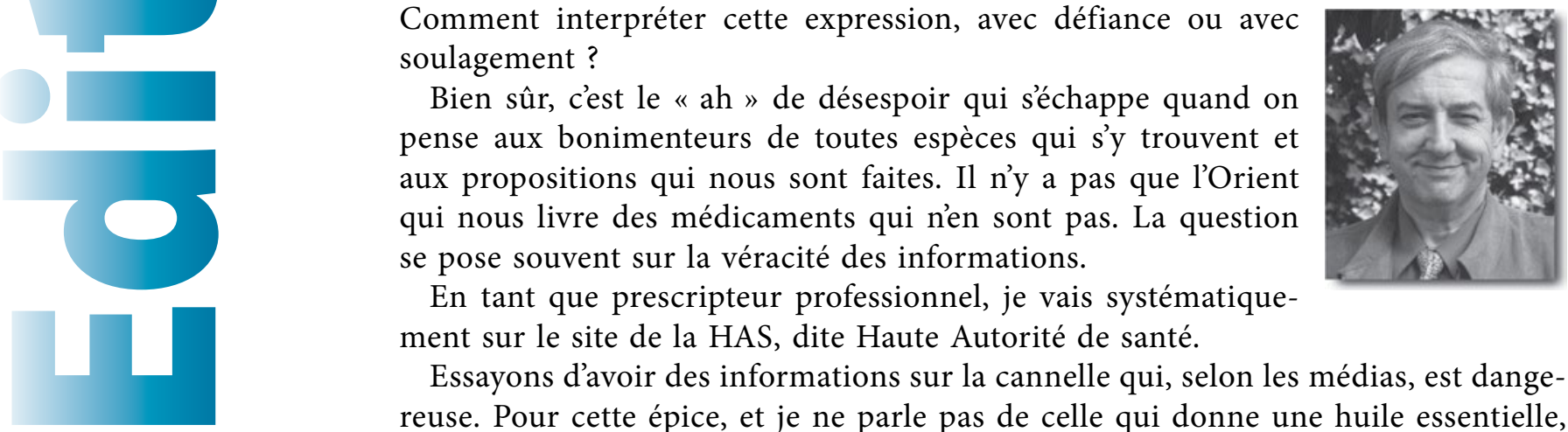
ment sur le site de la HAS, dite Haute Autorité de santé.

Essayons d'avoir des informations sur la cannelle qui, selon les médias, est dangereuse. Pour cette épice, et je ne parle pas de celle qui donne une huile essentielle, mais de celle qui se trouve dans nos mets et entremets, il n'y a aucune donnée. Si je vais sur le site de Santé Canada, je vais pouvoir lire des informations sur Cinnamomum verum. Il me faut cependant vérifier sur USDA Taxonomie des plantes de GRIN que Cinnamomum verum Presl. correspond bien à Cinnamomum zeylanicum Blume. Cependant, je n'apprendrai rien sur la cannelle du pâtissier la Cinnamomum cassia.

Il faut aller sur le site http://www.anses.fr/Documents/NUT2007sa0231.pdf pour trouver une indication quant à un danger de la consommation de cannelle de Chine. Encore faut-il trouver le mot "coumarine " qui y mène. Or, c'est une question à l'Assemblée qui y conduit en 2007 avec une réponse en $2010^{1}$ qui stipule laconiquement : "La cannelle fait partie de la catégorie des arômes et ingrédients alimentaires possédant des propriétés aromatisantes, actuellement régis par la directive 88/388/CE du 22 juin 1988. Cette directive est remplacée par le règlement (CE) $n^{\circ} 1334 / 2008 d u$ 16 décembre 2008 qui entrera en vigueur le 20 janvier 2011. " et "Dans l'attente, l'AFSSA a lancé le dispositif de vigilance en octobre 2009. "

"Ah, Internet! " pourrait aussi être un cri de jouissance quand on pense aux sources qui nous font part des recherches dans le domaine de la plante médicinale, ou de la plante pour laquelle des essais montrent une activité intéressante. Cela est le cas pour le poivre noir, Nepeta menthoides, Viola tricolor et la spécialité italienne Cistimev que nous rapportons dans les Actualités.

Depuis que la plante médicinale est tombée dans le giron du complément alimentaire, les études sont devenues rares en Europe ou ne paraissent pas dans les communications.

Devant le marasme des suppressions de remboursements de nombreux "petits » médicaments, la médecine de ville est presque orpheline, et les facultés de médecine qui sont prévues pour la recherche et l'avancée de la médecine se rendent 
lentement compte du désert pharmaceutique et bientôt médical de notre pays. Les médecins à exercice particulier (MEP), dont les phytoaromathérapeutes, savent encore répondre aux problèmes du quotidien.

Et il faut encourager les futurs phytothérapeutes, non à se distinguer des autres, mais à savoir se débrouiller mieux que les autres.

P. Goetz

Rédacteur en chef Dumenat de phytothérapie, Paris-XIII, F-93017 Bobigny cedex, France

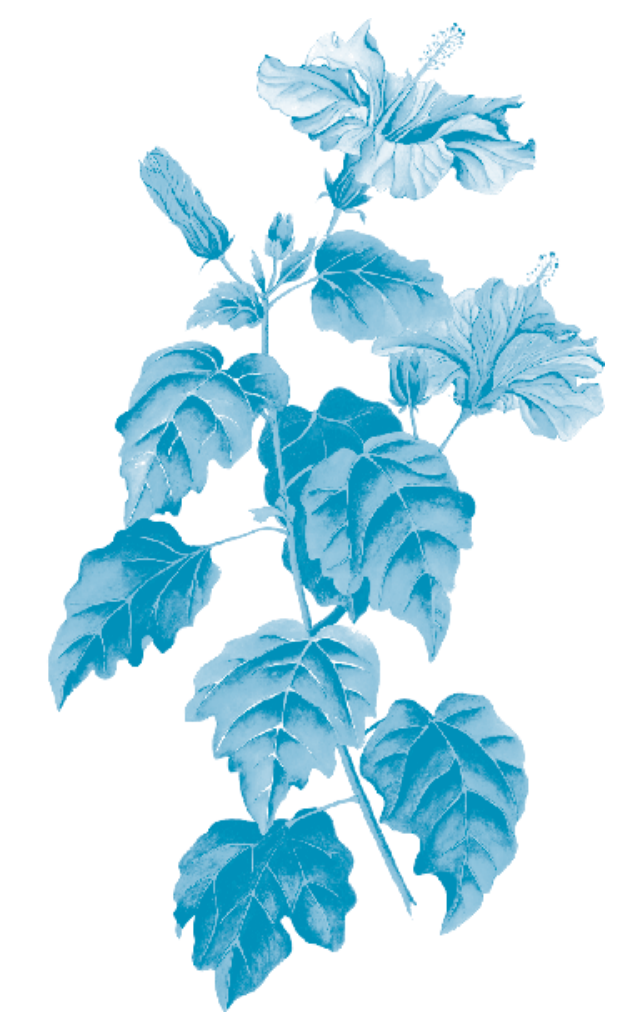

